\title{
Medical Overuse in the Iranian Healthcare System: A Systematic Scoping Review and Practical Recommendations for Decreasing Medical Overuse During Unexpected COVID-19 Pandemic Opportunity
}

This article was published in the following Dove Press journal: Risk Management and Healthcare Policy

\author{
Mohammad Zakaria Pezeshki iD \\ Ali Janati ${ }^{2}$ \\ Morteza Arab-Zozani (D) 3 3,4 \\ 'Social Determinants of Health Research \\ Center, Department of Community and \\ Family Medicine, Tabriz Medical School, \\ Tabriz University of Medical Sciences, \\ Tabriz, Iran; ${ }^{2}$ Iranian Center of Excellence \\ in Health Management, Department of \\ Health Services Management, School of \\ Management and Medical Informatics, \\ Tabriz University of Medical Sciences, \\ Tabriz, Iran; ${ }^{3}$ Social Determinants of \\ Health Research Center, Birjand \\ University of Medical Sciences, Birjand, \\ Iran; ${ }^{4}$ Student Research Committee, \\ Tabriz University of Medical Sciences, \\ Tabriz, Iran
}

Purpose: To perform an inclusive search for original studies that report medical overuse in the Iranian healthcare system and discovering the area of overuse.

Patients and Methods: A systematic search of the literature is conducted in bibliographic databases including PubMed, Embase, Scopus, Web of Sciences, Cochrane and Scientific Information Database using a comprehensive search strategy without time limit until the end of 2018, updated by 1 July 2020, accomplished by reference tracking, author contacting and expert consultation to identify studies on the overuse of medical care.

Results: We reviewed 4124 published articles based on predetermined inclusion criteria. The author's consensus included a total of 41 articles. Of these, 32 were in English and 9 in Farsi, published between 1975-2019. The result categorized into two distinct clinical areas: treatment (18 articles) and diagnostic (23 articles) services. Almost all of the studies only described the magnitude of unnecessary overuse. Unnecessary overuse of antibiotics, MRI, and CT-scan were the most reported topics. The ranges of their overuse proportion were as follows: antibiotic (31 to 97\%); MRI (33 to $88 \%$ ), and CT-scan (19 to $50 \%$ ).

Conclusion: Our review showed, even so, the magnitude of unnecessary overuse of medical services is high but there are only a few interventional studies in clinical and administrative level for finding effective methods for decreasing these unnecessary services. Researchers should be encouraged to conducting interventional studies. We suggest the ministry of health to use the golden opportunity of COVID-19 epidemic for designing Iran national policy and action plan for controlling and preventing unnecessary healthcare services and including a section for "Interventional Research" in the action plan.

Keywords: medical overuse, healthcare system, COVID-19, Iran

\section{Introduction}

Medical overuse means services that are more harmful than beneficial, does not seem to increase the quality and quantity of life, impose excessive cost on the patients and their healthcare system, has low quality and if the patient has enough information, he or she will not ask for it. ${ }^{1,2}$
Correspondence: Morteza Arab-Zozan Tel +989153317843

Email arab.hta@gmail.com
Risk Management and Healthcare Policy 2020: I 3 I I03-I I I0

submit your manuscrip (c) (i) (5) 2020 Pezeshki et al. This work is published and licensed by Dove Medical Press Limited. The full terms of this license are available at https://www.dovepress.com/terms. cc. ${ }_{\mathrm{BY}} \mathrm{NC}$ php and incorporate the Creative Commons Attribution - Non Commercial (unported, v3.0) License (http://creativecommons.org/licenses/by-nc/3.0/). By accessing the work you hereby accept the Terms. Non-commercial uses of the work are permitted without any further permission from Dove Medical Press Limited, provided the work is properly attributed. For permission for commercial use of this work, please see paragraphs 4.2 and 5 of our Terms (https://www.dovepress.com/terms.php). 
Overuse can take place in different areas including medication, test, or procedure. ${ }^{3}$ Recent studies have shown that overuse of tests and treatments can lead to serious consequences on patients in six domains including physical, psychological, social, financial, treatment burden, and dissatisfaction with healthcare. ${ }^{4}$ Medical overuse can delay access to the goals of health systems-improved health, responsiveness, financial risk protection, and efficiency-by increasing cost and decreasing the quality of medical care. ${ }^{5}$

Given the fact that medical overuse is one of the problems that can make system performances problematic, its identification is of great importance for a health system. ${ }^{6}$ Also, overuse in medical care is one of the obstacles to achieving universal health coverage (UHC). ${ }^{7}$ If we want to achieve better UHC, we need to be able to manage costs, and one of the most important tasks in this direction is to reduce overuse in medical services. ${ }^{8,9}$

Over the years, many efforts have been made to identify overuse in medical care across health systems around the world. ${ }^{10,11}$ In Iran, as in many other countries, there is little evidence about the amount of medical overuse in the healthcare system. ${ }^{1}$ So, the identification of medical overuse is an essential issue for the Iranian healthcare system and also helps health policymakers, health and medical managers, researchers, general practitioners, patients, and their families to cope with harms, costs, and quality of services. Ultimately, identifying the overuse of medical care can bring our health system to balance in the right use of services. Thus, the objectives of this systematic scoping review were 1) to review the literature on the overuse of medical care, (2) to identify the areas in which the overuse of medical care take placed (3) to determine the rate of overuse of medical care in the Iranian healthcare system and its drivers and (4) to identify the interventional studies in clinical and administrative level for decreasing the rate of overuse.

\section{Materials and Methods}

We conducted a systematic scoping review on medical overuse following the PRISMA-ScR checklist (supplementary material) and the five stages outlined in the Arksey and O’Malley framework. ${ }^{12}$ The review protocol was registered in PROSPERO before starting our study (registration no. CRD42017075481) and published in BMJ Open journal. ${ }^{1}$

\section{Stage I: Identifying Research Questions}

The following questions guided this scoping review of medical overuse in the Iranian healthcare system: How much literatures have dealt with this issue in the Iranian healthcare system? Which area does medical overuse occur? What is the rate of medical overuse in the Iranian healthcare system?

\section{Stage 2: Identifying Relevant Studies}

All original articles that investigated the overuse in medical care were included in the study. Of these, only studies were included those have addressed overuse in the Iranian healthcare system. All the included studies were limited in English and Farsi languages. Articles were excluded if the researchers did not have access to the Full-text.

We searched six databases including PubMed, Web of Science, Embase, Scopus, Cochrane and Scientific Information Database (SID) without a time limit until the end of 2018 (31 December 2018). We also contacted the authors of included studies and use reference tracks to get the articles we probably did not find in the search. We used a set of Medical Subject Headings (MeSH) terms and free terms to maximize the sensitivity of the search. For more information on search strategy, see study protocol at: https://bmjopen.bmj.com/content/8/4/e020355\#ref-17. ${ }^{1}$

After the article was finished and before the article was published, we searched the PubMed database again and updated our results until July 1, 2020. Details about search strategy are provided in the supplementary material.

\section{Stages 3 and 4: Study Selection and Data Charting Process}

After the search was completed, duplicate records were removed. Then, two reviewers screened the records based on the title, abstract and full text, and extracted the data about authors, publication year, type of study, study population, type of service, clinical area, and overuse rate or range. All potential disagreements in each level of study were resolved by consensus with a third researcher.

\section{Stage 5: Summarizing Results}

We categorized the results of the included studies based on publication year, clinical area, type of service (treatment and diagnostic area), and range or rate of overuse. 


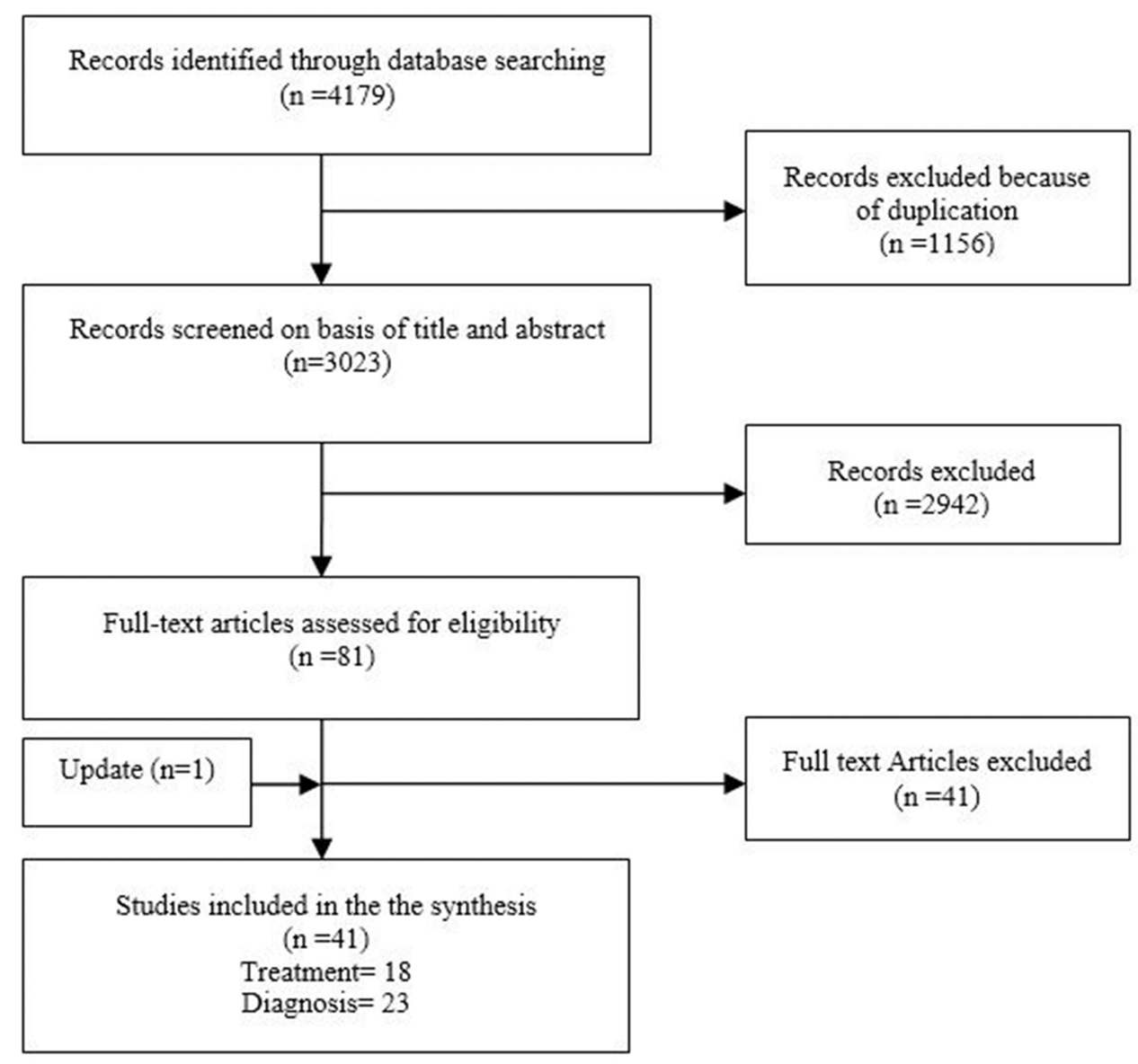

Figure I Study flow diagram.

\section{Results}

Initially, a total of 4179 records were screened. After removing duplicates, 3023 records were considered for eligibility. Of these, 41 studies were included. The study selection process is outlined in the Preferred Reporting Items for Systematic Reviews and Meta-analysis (PRISMA) diagram (Figure 1).

Most studies were published in English (78.04\%). Included studies published between 1975 and 2019. Most studies were published in 2014 (25\%), 2012 (15\%) and 2011 (12.5\%). Also, in terms of design, 38 were crosssectional, and three RCT studies. The summary characteristics of the included studies are shown in Table 1.

The result categorized into two distinct clinical areas: treatment (18 articles), and diagnostic (23 articles) area. Unnecessary overuse of Antibiotics, MRI, and CT-scan were the most reported topics. The ranges of their overuse proportion were as follows; Antibiotic (31 to 97\%); MRI (33 to $88 \%$ ), and CT-scan (19 to 50\%). Among the studies in the area of treatment, the most studied were antibiotics
(7 studies, 38.8\%), and three studies (16.6\%) did not compare the results with any other standard. Also, among the studies in the area of diagnosis, the most studied were related to MRI (4 studies, 17.3\%), and CT (4 studies, 17.3\%), and three studies (13\%) did not compare the results with any other standard. For more details see Tables 2 and 3.

\section{Discussion}

This systematic scoping review aimed to perform an inclusive search for original studies that report medical overuse in the Iranian healthcare system. Finally, 41 original studies were included in our study, of which 18 articles related to the treatment area and 23 articles related to the diagnostic area. Antibiotics and MRI were the most reported issues in each category where overuse has been reported.

Tables 2 and 3 shows the majority of studies only have focused on the magnitude of unnecessary diagnostic and treatment services. There are only a few interventional 
Table I The Summary Characteristics of the Included Studies

\begin{tabular}{|c|c|c|c|c|}
\hline Authors & Year & Language & Study Design & Sample Size \\
\hline Ahmadi et al $^{13}$ & 2006 & $\mathrm{Fa}$ & Cross-Sectional & 400 \\
\hline Ahmadizar et al $^{14}$ & 2011 & En & Cross-Sectional & $4,456,755$ \\
\hline Amidi et al $^{15}$ & 1975 & En & Cross-Sectional & 40 \\
\hline Alavi et al ${ }^{16}$ & 2014 & En & Cross-Sectional & 410 \\
\hline Alavi et al ${ }^{17}$ & 2014 & En & Cross-Sectional & 8586 \\
\hline Azami et al $^{18}$ & 2006 & $\mathrm{Fa}$ & Cross-Sectional & 150 \\
\hline Ahmadi et al ${ }^{19}$ & 2014 & En & Cross-Sectional & 1309 \\
\hline Alizadeh et $\mathrm{al}^{20}$ & 2012 & En & RCT & 200 \\
\hline Bijani et $\mathrm{al}^{21}$ & 2014 & En & Cross-Sectional & 1543 \\
\hline Hatam et $\mathrm{al}^{22}$ & 2011 & En & Cross-Sectional & 1000 \\
\hline Khakhshour et $\mathrm{al}^{23}$ & 2011 & $\mathrm{Fa}$ & Cross-Sectional & 292 \\
\hline Refahi et $\mathrm{al}^{24}$ & 2016 & En & Cross-Sectional & 115 \\
\hline Sobhani et $\mathrm{al}^{25}$ & 2001 & $\mathrm{Fa}$ & Cross-Sectional & 4750 \\
\hline Saadat et $\mathrm{al}^{26}$ & 2008 & En & Cross-Sectional & 1650 \\
\hline Sadeghi et $\mathrm{al}^{27}$ & 2015 & $\mathrm{Fa}$ & Cross-Sectional & 2105 \\
\hline Taghizadeh et $\mathrm{al}^{28}$ & 2013 & En & Cross-Sectional & 234 \\
\hline Zargar et $\mathrm{al}^{29}$ & 2014 & En & Cross-Sectional & 400 \\
\hline Vessal et $\mathrm{al}^{30}$ & 2011 & En & Cross-Sectional & 155 \\
\hline Bakhit et $\mathrm{al}^{3 !}$ & 2014 & En & Cross-Sectional & 270 \\
\hline Bayani et $\mathrm{al}^{32}$ & 2014 & $\mathrm{Fa}$ & Cross-Sectional & 400 \\
\hline Bilehjani et $\mathrm{al}^{33}$ & 2017 & En & Cross-Sectional & 620 \\
\hline Davoodian et $\mathrm{al}^{34}$ & 2012 & En & Cross-Sectional & 206 \\
\hline Eini et $\mathrm{al}^{35}$ & 2012 & $\mathrm{Fa}$ & Cross-Sectional & 100 \\
\hline Fard et $\mathrm{al}^{36}$ & 2001 & En & Cross-Sectional & 279 \\
\hline Forouzanfar et $\mathrm{al}^{37}$ & 2014 & En & Cross-Sectional & 2607 \\
\hline Ghadimi et $\mathrm{al}^{38}$ & 2011 & En & Cross-Sectional & 2041 \\
\hline Ghaffarpasand et al ${ }^{39}$ & 2011 & En & Cross-Sectional & 1679 \\
\hline Ghazizadeh et $\mathrm{al}^{40}$ & 2009 & En & $\mathrm{RCT}$ & 60 \\
\hline Jame et $\mathrm{al}^{4 !}$ & 2014 & En & Cross-Sectional & 400 \\
\hline Moussavi et al ${ }^{42}$ & 2015 & En & RCT & 100 \\
\hline Khaji et $\mathrm{al}^{43}$ & 2006 & En & Cross-Sectional & 1209 \\
\hline Meidani et $\mathrm{al}^{44}$ & 2017 & $\mathrm{Fa}$ & Cross-Sectional & 361 \\
\hline Meidani et $\mathrm{al}^{45}$ & 2016 & En & Cross-Sectional & 384 \\
\hline Memari et $\mathrm{al}^{46}$ & 2012 & En & Cross-Sectional & 345 \\
\hline Moghimi et al ${ }^{47}$ & 2008 & $\mathrm{Fa}$ & Cross-Sectional & 1220 \\
\hline Mohammadi et $\mathrm{al}^{48}$ & 2016 & En & Cross-Sectional & 279 \\
\hline Mokhtari et al ${ }^{49}$ & 2014 & En & Cross-Sectional & 1219 \\
\hline Nikbakhsh et a $\left.\right|^{50}$ & 2010 & En & Cross-Sectional & 498 \\
\hline Raji et $\mathrm{al}^{51}$ & 2018 & En & Cross-Sectional & 112 \\
\hline Paydar et $\mathrm{al}^{52}$ & 2012 & En & Cross-Sectional & 5091 \\
\hline Saboor et $\mathrm{al}^{53}$ & 2019 & EN & cross-sectional & |59| \\
\hline
\end{tabular}

studies regarding diagnostic and treatment services. Also, there is not any study regarding unnecessary clinical preventive services like unnecessary check-ups and also unnecessary public health services. Unfortunately, as the Tables show there is not any study at the regional or national level that clarifies the drivers of unnecessary services in Iran and how to address them. To address the shortage of study regarding the interventions for decreasing the overuse rate in Iran we already conducted qualitative research at the national level to clarify the drivers of overuse and strategies for controlling these drivers in Iran. In this qualitative study, we interviewed 21 well respected old hand policymakers and researchers of Iran. After analyzing the interview, our study showed that the main drivers of unnecessary overuse in the Iranian healthcare system are physician, patient, organizational, 
Table 2 The Characteristics of Included Studies in Treatment Area

\begin{tabular}{|c|c|c|c|c|}
\hline Authors & $\begin{array}{l}\text { Clinical } \\
\text { Domain }\end{array}$ & Subject & $\begin{array}{l}\text { The Ranges of Overuse } \\
\text { Proportion (\%) }\end{array}$ & Standard \\
\hline Amidi et al $^{15}$ & Treatment & Antibiotic & 92.5 & Clinical guideline \\
\hline Khakhshour et $\mathrm{al}^{23}$ & Treatment & Antibiotic & 70 & Clinical guideline \\
\hline Alavi et al ${ }^{16}$ & Treatment & Antibiotic & 41.4 & Clinical guideline \\
\hline Vessal et $\mathrm{al}^{30}$ & Treatment & Antibiotic & 31.6 & $\begin{array}{l}\text { American Society of Hospital Pharmacists } \\
\text { (ASHP) guidelines }\end{array}$ \\
\hline Hatam et $\mathrm{al}^{22}$ & Treatment & Antibiotic & 98 & ASHP \\
\hline Alavi et al ${ }^{17}$ & Treatment & Antibiotic & 44 & Mangram's guideline \\
\hline Taghizadeh et $\mathrm{al}^{28}$ & Treatment & Antibiotic & 61 & NR \\
\hline Ahmadizar et al ${ }^{14}$ & Treatment & $\begin{array}{l}\text { Drug-Drug } \\
\text { Interaction }\end{array}$ & 0.77 & National guideline \\
\hline Bijani et $\mathrm{al}^{21}$ & Treatment & Polypharmacy & $16.5-35.1$ & National guideline \\
\hline Sobhani et $\mathrm{al}^{25}$ & Treatment & Polypharmacy & 88 & NR \\
\hline Ahmadi et al $^{13}$ & Treatment & Polypharmacy & 39.6 & National guideline \\
\hline Azami et al $^{18}$ & Treatment & Blood transfusion & 26.8 & Scientific criteria \\
\hline Ahmadi et al ${ }^{19}$ & Treatment & $\begin{array}{l}\text { Intravenous } \\
\text { Acetaminophen }\end{array}$ & NR & NR \\
\hline Alizadeh et $\mathrm{al}^{20}$ & Treatment & Heparin & NR & Heparinization protocol \\
\hline Ghadimi et $\mathrm{al}^{38}$ & Treatment & Prescribing pattern & 30 & Beers criteria and $\mathrm{WHO}$ indicators \\
\hline Ghazizadeh et al ${ }^{40}$ & Treatment & $\mathrm{GnRH}$ antagonist & NR & Study protocol \\
\hline Memari et al ${ }^{46}$ & Treatment & $\begin{array}{l}\text { Psychotropic } \\
\text { medication }\end{array}$ & 80 & DSM-IV-TR criteria \\
\hline Saboor et $\mathrm{al}^{53}$ & Treatment & $\begin{array}{l}\text { Inappropriate } \\
\text { medication }\end{array}$ & 26 & Beers' criteria 2012 \\
\hline
\end{tabular}

Abbreviation: NR, not reported.

socio-cultural, market, and mass media factors. Also, a Policy Delphi analysis as part of our national study and based on the key informant's opinion, ${ }^{54,55}$ showed that the main interventions for decreasing unnecessary overuse of medical services include; implementing strategic purchasing, active engaging of insurance companies, promoting payment system, use of clinical practice guideline in decision making, and increasing political commitment and reducing conflicts of interest. We are going to publish the results of our study in detail. COVID-19 pandemic has created a golden opportunity for addressing the drivers of unnecessary overuse of medical services by countries because of the three main reasons: 1) There is a shortage of healthcare resources for controlling COVID-19 pandemic and unnecessary services waste the resources 2) Overuses of healthcare services unnecessarily expose the patients and healthy individuals to the virus in outpatient clinics and hospitals, 3) Overuse of medications may suppress the immune response and predispose people to COVID-19 infection. Our preliminary search shows that the COVID-19 pandemic has decreased the use of several clinical interventions in countries $^{56,57}$ for example screening tests, ${ }^{58}$ admission and hospitalization, ${ }^{59}$ and elective surgeries. ${ }^{60,61}$ Considerable proportions of these clinical interventions are unnecessary. We suggest the Iranian ministry of health to use the golden opportunity of COVOD-19 pandemic to develop national policy and action plans for controlling and preventing unnecessary healthcare services in Iran. These policies will facilitate the controlling of the COVID-19 epidemic and preventing underuse of necessary services during the COVID-19 epidemic and after the end of the epidemic.

Since this study was the first study in this field in Iran, there have been some limitations in conducting the study. One of the limitations has been related to the search strategy and how to search, which has made it difficult to research in this area due to the wide range of keywords. Researchers have tried to cover this limitation as much as possible by selecting multiple keywords, searching multiple databases, and using reference tracking and author contacting. Another limitation is the lack of evidence for some of the purposes of the study. For example, there has been no study on interventions to prevent medical overuse at the regional or national level, and we have limited 
Table 3 The Characteristics of Included Studies in Diagnostic Area

\begin{tabular}{|c|c|c|c|c|}
\hline Authors & $\begin{array}{l}\text { Clinical } \\
\text { Domain }\end{array}$ & Subject & $\begin{array}{l}\text { The Ranges of Overuse } \\
\text { Proportion (\%) }\end{array}$ & Standard \\
\hline Refahi et $\mathrm{al}^{24}$ & Diagnostic & MRI & 45.2 & Local guideline \\
\hline Zargar et $\mathrm{al}^{29}$ & Diagnostic & MRI & 46.5 & Clinical guideline \\
\hline Saadat et $\mathrm{al}^{26}$ & Diagnostic & MRI & 82.8 & Clinical guideline \\
\hline Sadeghi et $\mathrm{al}^{27}$ & Diagnostic & MRI & 76 & Clinical guideline \\
\hline Bakhit et $\mathrm{al}^{3 !}$ & Diagnostic & Diagnosis of dizziness & NR & Clinical guideline \\
\hline Bayani et $\mathrm{al}^{32}$ & Diagnostic & $\begin{array}{l}\text { Clinical diagnosis and candida } \\
\text { culture }\end{array}$ & NR & Clinical guideline \\
\hline Bilehjani et $\mathrm{al}^{33}$ & Diagnostic & $\begin{array}{l}\text { Erythrocyte Sedimentation Rate } \\
\text { (ESR) }\end{array}$ & NR & NR \\
\hline Davoodian et $\mathrm{al}^{34}$ & Diagnostic & Urinary catheters & 20.6 & NR \\
\hline Eini et $\mathrm{al}^{35}$ & Diagnostic & Antibacterial therapy & 97 & Clinical guideline \\
\hline Fard et $\mathrm{al}^{36}$ & Diagnostic & $\begin{array}{l}\text { Venous duplex ultrasonography } \\
\text { (VDUS) }\end{array}$ & NR & Scientific criteria \\
\hline Forouzanfar et $\mathrm{al}^{37}$ & Diagnostic & Chest X-ray (CXR) & 7.5 & $\begin{array}{l}\text { Thoracic Injury Rule out Criteria } \\
\text { (TIRC) }\end{array}$ \\
\hline Ghaffarpasand et $\mathrm{al}^{39}$ & Diagnostic & Radiography & NR & ATLS protocol \\
\hline Jame et $\mathrm{al}^{41}$ & Diagnostic & Computed tomography & $\mid 9.8-51.6$ & Glasgow coma score \\
\hline Moussavi et al ${ }^{42}$ & Diagnostic & Computed tomography & NR & Glasgow coma score \\
\hline Khaji et al ${ }^{43}$ & Diagnostic & Computed tomography & 66.5 & Glasgow coma score \\
\hline Meidani et al ${ }^{44}$ & Diagnostic & Computed tomography & 14.1 & ACR criteria \\
\hline Meidani et $\mathrm{al}^{45}$ & Diagnostic & Laboratory test & 26.4 & ACR criteria \\
\hline Moghimi et $\mathrm{al}^{47}$ & Diagnostic & Preclinical test & $1.3-9.6$ & NR \\
\hline Mohammadi et $\mathrm{al}^{48}$ & Diagnostic & MRI & 33 & NICE and AHRQ guidelines \\
\hline Mokhtari et $\mathrm{a}^{49}$ & Diagnostic & $\begin{array}{l}\text { Venous thromboembolism (VTE) } \\
\text { prophylaxis }\end{array}$ & NR & ACCP guidelines \\
\hline Nikbakhsh et al ${ }^{50}$ & Diagnostic & electrocardiogram (ECG) & 77.3 & $\begin{array}{l}\text { American Society of Anesthesiologists } \\
\text { status (ASA) criteria }\end{array}$ \\
\hline Raji et $\mathrm{al}^{51}$ & Diagnostic & Pulmonary $\mathrm{CT}$ angiography & NR & Geneva score and Wells' criteria \\
\hline Paydar et $\mathrm{al}^{52}$ & Diagnostic & $\begin{array}{l}\text { Routine chest radiography for } \\
\text { stable blunt trauma }\end{array}$ & 19.8 & ATLS \\
\hline Salari et $\mathrm{al}^{62}$ & Diagnostic & Knee MRI & 24 & National guideline \\
\hline
\end{tabular}

Abbreviation: NR, not reported.

evidence. However, it is one of the interesting and important results of the study.

\section{Conclusion}

Our systematic review shows even so the magnitude of unnecessary overuse of medical services is high but there are only a few interventional studies at the clinical and administrative levels for finding effective methods for decreasing these unnecessary services. Researchers should be encouraged for conducting such researches. It is necessary to be included a section for "Interventional Research" in the action plans we suggest to the ministry of health for controlling and preventing unnecessary healthcare services in Iran.

\section{Funding}

This work was supported by Tabriz University of Medical Sciences. Grant number 5/d/633456, 15 January 2018. (Ethical code for dissertation: IR.TBZMED.REC.1396.908).

\section{Disclosure}

The authors report no conflicts of interest in this work.

\section{References}

1. Arab-Zozani M, Pezeshki MZ, Khodayari-Zarnaq R, Janati A. Medical overuse in the Iranian healthcare system: a systematic review protocol. BMJ open. 2018;8(4):e020355.

2. Brownlee S, Chalkidou K, Doust J, et al. Evidence for overuse of medical services around the world. Lancet. 2017;390(10090):156-168. 
3. Morgan DJ, Dhruva SS, Coon ER, Wright SM, Korenstein D. 2017 update on medical overuse: a systematic review. JAMA internal med. 2018;178(1):110-115.

4. Korenstein D, Chimonas S, Barrow B, Keyhani S, Troy A, LipitzSnyderman A. Development of a conceptual map of negative consequences for patients of overuse of medical tests and treatments. JAMA Intern Med. 2018;178(10):1401. doi:10.1001/jamainternmed.2018.3573

5. Korenstein D, Falk R, Howell EA, Bishop T, Keyhani S. Overuse of health care services in the United States: an understudied problem. Arch internal med. 2012;172(2):171-178.

6. Morgan DJ, Leppin A, Smith CD, Korenstein D. A practical framework for understanding and reducing medical overuse: conceptualizing overuse through the patient-clinician interaction. J hospital med. 2017;12(5):346.

7. Kleinert S, Horton RJTL. From universal health coverage to right care for health. Lancet. 2017;390(10090):101-102.

8. Berwick DMJTL. Avoiding overuse-the next quality frontier. Lancet. 2017;390(10090):102-104.

9. Elshaug AG, Rosenthal MB, Lavis JN, et al. Levers for addressing medical underuse and overuse: achieving high-value health care. Lancet. 2017;390(10090):191-202.

10. Rosenberg A, Agiro A, Gottlieb M, et al. Early trends among seven recommendations from the Choosing Wisely campaign. JAMA internal med. 2015;175(12):1913-1920.

11. Rumball-Smith J, Shekelle PG, Bates DWJJ. Using the electronic health record to understand and minimize overuse. Jama. 2017;317(3):257-258.

12. Arksey H, O’Malley L. Scoping studies: towards a methodological framework. Int J Soc Res Methodol. 2005;8(1):19-32. doi:10.1080/ 1364557032000119616

13. Ahmadi B, Alimohamadian M, Mahmoodi M. Polypharmacy among older adults in Tehran. Tehran Univ Med J TUMS Publ. 2006;64 (9):65-71.

14. Ahmadizar F, Soleymani F, Abdollahi M. Study of drug-drug interactions in prescriptions of general practitioners and specialists in Iran 2007-2009. Iran J Pharm Res. 2011;10(4):921-931.

15. Amidi S, Solter S, Rashidian B, Zokaian AR, Razmjoian F. Antibiotic use and abuse among physicians in private practice in Shiraz, Iran. Med Care. 1975;13(4):341-345. doi:10.1097/00005650-197504000-00006

16. Alavi SM, Roozbeh F, Behmanesh F, Alavi L. Antibiotics use patterns for surgical prophylaxis site infection in different surgical wards of a teaching hospital in Ahvaz, Iran. Jundishapur J Microbiol. 2014;7(8):11. doi:10.5812/jjm.12251

17. Alavi SM, Sharifi M, Eghtesad M. Bacterial sepsis: challenges of diagnosis and treatment in a teaching hospital Southwest of Iran. Jundishapur J Microbiol. 2014;7(3):3. doi:10.5812/jjm.9082

18. Azami A, Amani F, Khorasani S. Unnecessary blood and blood products transfusion to patients admitted to Ardabil Dr Fatemi Hospital, 2003. J Ardabil Univ Med Sci. 2006;6(4):345-350.

19. Ahmadi K, Hashemian AM, Pishbin E, Sharif-Alhoseini M, RahimiMovaghar V. Impact of intravenous acetaminophen therapy on the necessity of cervical spine imaging in patients with cervical spine trauma. Chin j Traumatology. 2014;17(4):204-207.

20. Alizadeh A, Yazdi AH, Kafi M, Rad MA, Moradi M, Emkanjoo Z. Predictors of local venous complications resulting from electrophysiological procedures. Cardiol J. 2012;19(1):15-19. doi:10.5603/ CJ.2012.0004

21. Bijani A, Roshan ARH, Yazdanpour S, Hosseini SR. Are older women likely to use medicines than older men? (Results from AHAP study). Caspian J Internal Med. 2014;5(2):77-81.

22. Hatam N, Askarian M, Moravveji AR, Assadian O. Economic burden of inappropriate antibiotic use for prophylactic purpose in Shiraz, Iran. Iran Red Crescent Med J. 2011;13(4):234-238.

23. Khakhshour A, Taherpour M, Khorashadi Zadeh F, Maddi I, Nojomi $\mathrm{S}$, Shaikhi Z. Unnecessary antibiotic therapy in children with diarrhea may cause antibiotic resistance. J North Khorasan Univ Med Sci. 2011;3(2):29-33. doi:10.29252/jnkums.3.2.29
24. Refahi S, Kachooei AR, Farsadpour M, et al. IS PRESCRIPTION OF KNEE MRI ACCORDING TO STANDARD CLINICAL GUIDELINE? Acta Med Mediterr. 2016;32:1207-1211.

25. Sobhani A, Shodjai H. Prevalence of polypharmacy and correlations with sex, age and drug regimen in insurance prescription. J Guilan UnivMed Sci. 2001.

26. Saadat S, Ghodsi SM, Firouznia K, Etminan M, Goudarzi K, Naieni $\mathrm{KH}$. Overuse or underuse of MRI scanners in private radiology centers in Tehran. Int J Technol Assess Health Care. 2008;24 (3):277-281. doi:10.1017/S0266462308080379

27. Sadeghi A, Keshavarz K, Ahmadzadeh MS, Yousefi A. Survey of Appropriate Use of Magnetic Resonance Imaging Services Provided in Shahid Chamran Hospital of Shiraz. J Health Res Community. 2015;1(3):33-40.

28. Taghizadeh S, Haghdoost M, Mashrabi O, Zeynalikhasraghi Z. Antibiotic usage in intensive care units of Tabriz Imam Reza hospital, 2011. Am J Infect Dis. 2013;9(4):123-128. doi:10.3844/ajidsp.2013.130.135

29. Zargar BJS, Sari AA, Majdzadeh R, Rashidian A, Arab M, Rahmani $H$. The extent of inappropriate use of magnetic resonance imaging in low back pain and its contributory factors. Int J Prev Med. 2014;5 (8):1029-1036.

30. Vessal G, Namazi S, Davarpanah MA, Foroughinia F. Evaluation of prophylactic antibiotic administration at the surgical ward of a major referral hospital, Islamic republic of Iran. East Mediterranean Health J. 2011;17(8):663-667. doi:10.26719/2011.17.8.663

31. Bakhit M, Heidarian A, Ehsani S, Delphi M, Latifi SM. Clinical assessment of dizzy patients: the necessity and role of diagnostic tests. Glob J Health Sci. 2014;6(3):194-199. doi:10.5539/gjhs.v6n3p194

32. Bayani M, Asghar Sefidgar SA, Basirat Z, et al. Association of clinical symptoms and laboratory results in diagnoses of Candida vaginitis. J Babol Univ Med Sci. 2014;16(1):50-55.

33. Bilehjani E, Fakhari S, Farzin H, et al. The correlation between preoperative erythrocyte sedimentation rate and postoperative outcome in adult cardiac surgery. Int J Gen Med. 2017;10:15-21. doi:10.2147/IJGM.S121904

34. Davoodian P, Nematee M, Sheikhvatan M. Inappropriate use of urinary catheters and its common complications in different hospital wards. Saudi j Kidney Dis Transplant. 2012;23(1):63-67.

35. Eini P, Mobaien A, Agha Sharif M. Importance of diagnostic laboratory methods of beta hemolytic streptococcus group A in comparison with clinical findings in the diagnosis of streptococcal sore throat and unnecessary antibacterial therapy. ISMJ. 2012;15(1):59-68.

36. Fard MN, Mostaan M, Anaraki M. Utility of lower-extremity duplex sonography in patients with venous thromboembolism. $J$ Clin Ultrasound. 2001;29(2):92-98. doi:10.1002/1097-0096(200102) 29:2<92::AID-JCU1004>3.0.CO;2-0

37. Forouzanfar MM, Safari S, Niazazari M, et al. Clinical decision rule to prevent unnecessary chest X-ray in patients with blunt multiple traumas. Emergency Med Australas. 2014;26(6):561-566. doi:10.1111/1742-6723.12302

38. Ghadimi H, Esmaily HM, Wahlstrom R. General practitioners' prescribing patterns for the elderly in a province of Iran. Pharmacoepidemiol Drug Saf. 2011;20(5):482-487. doi:10.1002/ pds. 2106

39. Ghaffarpasand F, Paydar S, Foroughi M, et al. Role of cervical spine radiography in the initial evaluation of stable high-energy blunt trauma patients. J Orthop Sci. 2011;16(5):498-502. doi:10.1007/ s00776-011-0132-5

40. Ghazizadeh S, Pourmatroud E, Shariat M, Masomi M, Bagheri M. Study of Positive and Negative Consequences of Using GnRH Antagonist in Intrauterine Insemination Cycles. Int J Fertil Sterility. 2009;3(2):56-61.

41. Jame SZB, Majdzadeh R, Sari AA, Rashidian A, Arab M, Rahmani H. Indications and Overuse of Computed Tomography in Minor Head Trauma. Iran Red Crescent Med J. 2014;16:5. 
42. Moussavi N, Davoodabadi AH, Atoof F, Razi SE, Behnampour M, Talari HR. Routine Chest Computed Tomography and Patient Outcome in Blunt Trauma. Arch Trauma Res. 2015;4(2):2. doi: 10.5812/atr.25299v2

43. Khaji A, Eftekhar B, Karbakhsh M, Ardalan KM. The use of head CT scanning in mild head injury. Neurosciences. 2006;11(4):248-251.

44. Meidani Z, Moosavi G, Hamidian Y, Farzandipour M, Aliasgharzadeh A, Nazemi BZ. Assessing the appropriate utilization of CT scan in triage units. Hospital. 2017;16(2):27-35.

45. Meidani Z, Farzandipour M, Farrokhian A, Haghighat M. A review on laboratory tests' utilization: A trigger for cutting costs and quality improvement in health care settings. Med J Islam Repub Iran. 2016;30:1.

46. Memari AH, Ziaee V, Beygi S, Moshayedi P, Mirfazeli FS. Overuse of psychotropic medications among children and adolescents with autism spectrum disorders: perspective from a developing country. Res Dev Disabil. 2012;33(2):563-569. doi:10.1016/j.ridd.2011.10.001

47. Moghimi M, Marashi S, Salehian M, Motavalizadeh K. Unnecessary paraclinical tests before elective surgeries. $J$ Iranian Soc Anesthesiology Intensive Care. 2008;30(62):33-70.

48. Mohammadi N, Farahmand F, Kharazi HH, Mojdehipanah H, Karampour H, Nojomi M. Appropriateness of physicians' lumbosacral MRI requests in private and public centers in Tehran, Iran. Med J Islam Repub Iran. 2016;30(1):1-7.

49. Mokhtari M, Attarian H, Norouzi M, et al. Venous thromboembolism risk assessment, prophylaxis practices and interventions for its improvement (AVAIL-ME Extension Project, Iran). Thromb Res. 2014;133(4):567-573. doi:10.1016/j.thromres.2014.01.006

50. Nikbakhsh N, Alijanpoor E, Adabi F. Preoperative medical evaluation in elective surgery versus standard criteria. Caspian J Internal Med. 2010;1(2):53-57.

51. Raji H, JavadMoosavi SA, Dastoorpoor M, Mohamadipour Z, Mousavi Ghanavati SP. Overuse and underuse of pulmonary CT angiography in patients with suspected pulmonary embolism. Med $J$ Islam Repub Iran. 2018;32(1):3. doi:10.14196/mjiri.32.3

52. Paydar S, Johari HG, Ghaffarpasand F, et al. The role of routine chest radiography in initial evaluation of stable blunt trauma patients. Am J Emergency Med. 2012;30(1):1-4. doi:10.1016/j.ajem.2010.08.010
53. Saboor M, Kamrani AA, Momtaz YA, Sahaf R. Prevalence and associated factors of potentially inappropriate medications among Iranian older adults. Medicinski Glasnik. 2019;16(1):121-127. doi:10.17392/989-19

54. Arab-Zozani M, Janati A, Zakaria Pezeshki M, Khodayari-Zarnaq R. Policy package for preventing overuse and underuse of health care services in the Iranian health care system: A study protocol. Med J Islam Repub Iran. 2019;33:86. doi:10.34171/mjiri.33.86

55. Arab-Zozani M, Pezeshki MZ, Janati A, Khodayari-zarnaq R. 6 Medical overuse: how to define, detect and prevent? BMJ Evidence Based Med. 2019;24(Suppl 2):A10-A10.

56. Emanuel E, Navathe A. Will 2020 Be the Year That Medicine Was Saved? The New York Times; 2020. https://www.nytimes.com/2020/ 04/14/opinion/coronavirus-hospitals.html. Accessed July 23, 2020.

57. Reisman J, Wexler A. Covid-19: exposing the lack of evidence-based practice in medicine. Hastings Center Report. 2020;50(3):77-78. doi: $10.1002 /$ hast. 1144

58. Bewley S. Things should never be the same again in the screening world. BMJ. 2020.

59. Arab-Zozani M, Pezeshki MZ, Khodayari-Zarnaq R, Janati A. Inappropriate rate of admission and hospitalization in the iranian hospitals: a systematic review and meta-analysis. Value Health Reg Issues. 2020;21:105-112. doi:10.1016/j.vhri.2019.07.011

60. Elshaug A, Duckett S. Hospitals have stopped unnecessary elective surgeries - and shouldn't restart them after the pandemic. Conversation. 2020. https://theconversation.com/hospitals-havestopped-unnecessary-elective-surgeries-and-shouldnt-restart-themafter-the-pandemic-136259

61. Prasad S. An Unexpected Opportunity Presented by the COVID-19 Pandemic. Clear Health. 2020. https:/www.realclearhealth.com/arti cles/2020/04/03/an_unexpected_opportunity_presented_by_the covid-19 pandemic_111011.html

62. Salari H, Omranikhoo H, Amini A, et al. Examining the amount of unnecessary knee MRI prescription in the MRI center of bushehr university of medical sciences in 2018. Evidence Based Health Policy Manage Econ. 2020;4(2):82-88.
Risk Management and Healthcare Policy

\section{Publish your work in this journal}

Risk Management and Healthcare Policy is an international, peerreviewed, open access journal focusing on all aspects of public health, policy, and preventative measures to promote good health and improve morbidity and mortality in the population. The journal welcomes submitted papers covering original research, basic science, clinical \& epidemiological studies, reviews and evaluations,

\section{Dovepress}

guidelines, expert opinion and commentary, case reports and extended reports. The manuscript management system is completely online and includes a very quick and fair peer-review system, which is all easy to use. Visit http://www.dovepress.com/testimonials.php to read real quotes from published authors. 